\title{
Fabrication of palladium nanowire array electrode for biofuel cell application
}

\author{
Gymama Slaughter and Tanmay Kulkarni \\ University of Maryland Baltimore County and Bioelectronics Laboratory \\ Department of Computer Science and Electrical Engineering \\ 1000 Hilltop Circle, Baltimore, MD 21250, USA \\ Tel.: +1 410455 8483; fax: +1 4104553969 .
}

Corresponding author: E-mail address: gslaught@umbc.edu

\begin{abstract}
Bioelectrocatalysis was demonstrated with palladium (Pd) nanowire array electrode via nonenzymatic and enzymatic methods for glucose, which was validated by the generation of anodic current in the presence of glucose. The vertically standing Pd nanowires used for the fabrication of the electrodes were on average $5.6 \mu \mathrm{m}$ in length and $64 \mathrm{~nm}$ in diameter. In comparison, the nonenzymatic bioanode exhibited lower current densities and required the application of larger overpotential which resulted in a large cell voltage drop $\left(\mathrm{V}_{\mathrm{oc}}=13.5 \mathrm{mV}\right)$ and limited power production when assembled as a biofuel cell under physiological conditions ( $\mathrm{pH} 7,0.1 \mathrm{M}$ phosphate buffer saline) with laccase covalently bounded to $\mathrm{Pd}$ nanowires as the biocathode. The glucose/ $\mathrm{O}_{2}$ biofuel cell was studied in phosphate buffer saline using the enzymatic bioanode that was developed with the co-immobilization of catalase and glucose oxidase on Pd nanowires and the laccase-Pd as the biocathode. The biofuel cell exhibited an open-circuit voltage of $0.506 \mathrm{~V}$, delivered a maximum power density of $72 \mu \mathrm{W} \mathrm{cm}$ at a cell voltage of $0.25 \mathrm{~V}$ and a short-circuit current density of $411 \mu \mathrm{A} \mathrm{cm}^{-2}$ when operating in 10 $\mathrm{mM}$ glucose. Such low-cost lightweight glucose/ $\mathrm{O}_{2}$ biofuel cells have a great promise to be optimized, miniaturized to power bio-implantable devices.
\end{abstract}

Keywords: Pd nanowires; nonenzymatic and enzymatic bioelectrocatalysis; glucose oxidase; biofuel cells

\section{Introduction}

The resurgent development of biofuel cell devices has been driven by the mass-market acceptance of conventional fuel cell technologies, in which many efforts have been devoted to biocatalytically modified electrode materials, specifically for sensor applications [1-8]. These research activities in biocatalytically modified metal electrodes have provided a significant technological foundation for current biofuel cell development. Enzymatic biofuel cells employ biocatalysts to convert the chemical free energy stored in biofuels, such as glucose directly into bioelectricity. The generation of electricity is a product of the oxidation of the biofuel and the reduction of molecular oxygen by inexpensive biocatalysts. Researched biofuel cells employ direct electron transfer, as well as employ mediator electron transfer [915]. Katz et al. [12] studied the immobilization of a biocatalyst and a mediator at both the anode and cathode of an enzymatic fuel cell and showed that a maximal power density of $4 \mu \mathrm{W} / \mathrm{cm}^{2}$ at a cell potential of $40 \mathrm{mV}$ can be obtained by operating in $1 \mathrm{mM}$ glucose $(\mathrm{pH} 7)$. Tsujimura et al. [13] demonstrated anodic oxidation of glucose in a compartmentless glucose-oxygen fuel cell using glucose dehydrogenase, and a power density of $58 \mu \mathrm{W} / \mathrm{cm}^{2}$ was achieved at a $\mathrm{pH}$ of 7 . To date, the development of stable and continuous enzymatic biofuel cells designed to catalyze the oxidation of fuel has been limited by low power densities [16-18].

Although Pd has been demonstrated to exhibit high degree of selectivity for glucose in nonenzymatic amperometric glucose sensing under high $\mathrm{pH}(0.1 \mathrm{M} \mathrm{NaOH})$ conditions [19-20], there are no reports of Pd being used in nonenzymatic glucose-based biofuel cell application due to the large overpotential of Pd. In this study, we describe the fabrication of the 
first glucose biofuel cell bioanode based on the combination of glucose oxidase and Pd nanowire array to reduce the overpotential in order to maximize electron transfer processes for glucose/ $\mathrm{O}_{2}$ biofuel cell applications. The Pd nanowire array electrodes realized from anodized aluminum oxide (AAO) template electrodeposition method [21- 22] exhibit a large surface area, which results in an increased number of adsorption sites for the immobilization of glucose oxidase. This further enables the electron generated during the biocatalysis to be directly transferred to the Pd electrode from the active center of glucose oxidase, thereby compensating for the large overpotential of bare Pd electrode. We also present the fabrication and electrochemical characterization of the enzymatic glucose biofuel cell based on Pd nanowires by combining the advantageous features of non-toxic biocatalytic systems to enhance the biofuel cell performance for application in miniaturized systems. The palladium nanowires maximize the surface area of the cells and may serve as an alternative nanostructured electrode material to CNTs that can help sustain the voltage generated, and thus increase the power densities of the cells.

\section{Experimental section}

\subsection{Chemicals}

Aluminum foils (99.9999\% purity, $0.25 \mathrm{~mm}$ thickness) were purchased from Alfa Aesar. Anodized Aluminum Oxide (AAO) templates with estimated porosity $15 \%$, were purchased from Synkera Technologies, Inc. Tetraamminepalladium (II) chloride monohydrate, ammonium chloride, glucose oxidase (GOx, EC 1.1.3.4 from Aspergillus niger), d-(+)glucose, catalase (EC 1.11.1.6 from bovine liver), laccase (EC 1.10.3.2 from Trametes versicolor), hydroxyethylmethacrylate (HEMA), tetraethyleneglycol diacrylate (TEGDA), 2,2-dimethoxy-2-phenylacetophenone (DMPA, 99\%), 3-aminopropyltrimethoxysilane ( $\gamma$-APS, 97\%), glutaraldehyde, ethyldimethyl-aminopropylcarbodiimide (EDC) and poly(ethylene glycol) methacrylate (PEGMA) were purchased from Sigma-Aldrich. The diacyrlate and methacrylate reagents were passed through an inhibitor removal column in order to remove the hydroquinone and monomethyl ether hydroquinone polymerization inhibitors before use. Acryloyl(polyethyleneglycol)- $\mathrm{N}$ hydroxysuccinamide (MW 3500), was purchased from Jenkem Technology. All supplementary chemicals were of analytical grades and solutions were prepared with $18.2 \mathrm{M} \Omega \mathrm{cm}$ Milli-Q water.

\subsection{Electrochemical deposition of Pd Nanowires}

Prior to electrodeposition, the anodized aluminum oxide (AAO, $3 \times 3 \mathrm{~mm}$ ) templates were degreased in acetone followed by drying under nitrogen flow. A thin film of $\mathrm{Au}(100 \AA)$ was sputtered onto one side of the AAO templates to provide an electrical conduction path for the electrodeposition of the Pd nanowires by exposing the pores of the AAO template to the underlying Au film. To create an electrical connection to the AAO electrodes, 4 x $10 \mathrm{~mm}$ strips of aluminum foil were degreased in acetone, and then dried in vacuum at $450{ }^{\circ} \mathrm{C}$ for $3 \mathrm{~h}$ and was attached to the Au sputtered side of the AAO substrate using silver epoxy (SEC 1233 ResinLab). Silicone epoxy was used for bioelectrode passivation and to define the electroactive area of the bioelectrodes. The passivation method employed also serve to seal the sides of the AAO templates. Furthermore, it prevents any breaking or swelling of the electrode material in contact with the electrolyte. The AAO template affixed to the aluminum foil (Al-AAO) was dried overnight at room temperature. Scheme 1 illustrates the process flow for preparing Pd nanowires. The Al-AAO template served as the working electrode in a three-electrode electrochemical cell setup with a platinum wire and a $\mathrm{Ag} / \mathrm{AgCl}_{\text {(sat) }}$ electrode as the counter and reference electrodes, respectively in a water jacketed electrochemical cell. The Al-AAO template was immersed in the electrodeposition solution containing $1 \mathrm{~g} / \mathrm{L} \mathrm{Pd}\left(\mathrm{NH}_{3}\right)_{4} \mathrm{Cl}_{2}(99.99 \%)$ and $10 \mathrm{~g} / \mathrm{L} \mathrm{NH}_{4} \mathrm{Cl}(99.99 \%)$ for $\sim 15$ minutes prior to electrochemically depositing $\mathrm{Pd}$ from the aqueous solution at a $\mathrm{pH}$ of 8 . The electrodeposition was conducted at $-600 \mathrm{mV}$ versus $\mathrm{Ag} / \mathrm{AgCl}$ at a temperature of $30{ }^{\circ} \mathrm{C}$ for $2 \mathrm{~h}$ using BASi potentiostat/galvanostats EC Epsilon. After electrodeposition, the substrate was rinsed in deionized water and the AAO template was etched away in $2 \mathrm{M} \mathrm{NaOH}$ for 6 min at room temperature with mild agitation. The resulting free standing Pd nanowire array electrodes were then rinsed three times with ethanol followed by deionized water. 


\subsection{Functionalization of palladium nanowires}

The surface of the as-prepared Pd nanowire bioelectrodes were subsequently functionalized by treatment with $\gamma$-APS, $0.1 \mathrm{vol} \%$ in ethanol at $40{ }^{\circ} \mathrm{C}$ for $30 \mathrm{~min}$ in order to introduce silane surface functionalities as previously reported [3]. After silanization, the Pd nanowire array bioelectrodes were rinsed by sequential washing for 1 minute in ethanol, and then in ethanol/water mixture $(1: 1, \mathrm{v} / \mathrm{v})$. Finally, the $\gamma$-APS coated Pd nanowire array bioelectrodes were cured at $110{ }^{\circ} \mathrm{C}$ for 20 minutes in a convection oven. And then, incubated in 6\% glutaraldehyde at room temperature for $30 \mathrm{~min}$. The surfaces of the Pd nanowires were thoroughly rinsed and placed in $0.1 \mathrm{M}$ phosphate buffer, $\mathrm{pH} 7$. This was followed by a derivatization step to create a continuous path of covalent bonding between the Pd nanowire bioelectrode surfaces and the biocatalysts.

\subsection{Preparation of bioelectrodes}

The biocatalyst immobilizations were achieved by incubating the $\gamma$-APS-aldehyde functionalized Pd nanowire bioelectrodes in the appropriate enzyme solution (bioanode: $1 \mathrm{mg} / \mathrm{mL}$ glucose oxidase and $0.5 \mathrm{mg} / \mathrm{mL}$ catalase or biocathode: $1 \mathrm{mg} / \mathrm{mL}$ laccase in in $0.05 \mathrm{M}$ phosphate buffer with $0.15 \mathrm{M} \mathrm{NaCl}(\mathrm{PBS}), \mathrm{pH}$ 7) for $30 \mathrm{~min}$. The surfaces were thoroughly rinsed in PBS and incubated for an additional $30 \mathrm{~min}$ in HEPES buffer containing 0.2 M EDC and 0.05 M PEG-NHS solution at room temperature in the dark. Finally, the electrodes were rinsed thoroughly in buffer.

The immobilized enzyme bioanode and biocathode surface were encapsulated with HEMA-based hydrogel membrane to enhance the lifetime of immobilized enzymes. The HEMA-based hydrogel was chosen because it allows efficient diffusion of glucose into the Pd nanowire matrix. The monomer mixture comprised of HEMA, PEGMA, TEGDA in a mole ratio of 80:10:10. DMPA, $4 \mathrm{wt} \%$, photoinitiator was then completely dissolved in the mixture and $5 \mu \mathrm{L}$ of the monomer mixture was solvent casted onto the Pd nanowire bioelectrodes. UV irradiation $\left(2.3 \mathrm{~W} / \mathrm{cm}^{2}, 366 \mathrm{~nm}\right.$, UVP Model CX-2000) was performed for 20 min to polymerize the methacrylates. The PEGMA monomer was added to the hydrogel formulation to provide for long-term stabilization of membrane-immobilized biocatalysts. This establishes PEG chains, set pendant to the polymer network, in the form of network supported polymer brushes. PEG chains are well known to stabilize proteins, preventing their denaturation and promoting long-term bioactivity [3].

\subsection{Electrochemical experiments}

Electrochemical characterizations were conducted on BASi potentiostat/galvanostats EC Epsilon at $37{ }^{\circ} \mathrm{C}$. The electrochemical experiments were performed in a conventional three-electrode cell with the exception of the biofuel cell characterizations. The $\mathrm{Ag} / \mathrm{AgCl}($ sat $)$ and $\mathrm{Pt}$ wire were used as the reference and counter electrode, respectively. Various glucose concentrations were investigated. The working buffer solution was $0.1 \mathrm{M}$ phosphate buffer unless otherwise indicated. All potentials referenced in the present work are measured against $\mathrm{Ag} / \mathrm{AgCl}$ reference electrode. The anodes were characterized using potentiostatic polarization curves generated by applying a series of potentials to the anode while measuring the resulting steady-state current density as a function of time. Cyclic voltammetry were conducted with scan rates of $20 \mathrm{mV} \mathrm{s}^{-1}$ and under air, unless otherwise indicated.

\subsection{Biofuel cell characterizations}

The biofuel cell characterizations were carried out in phosphate buffer saline $(\mathrm{pH} 7)$. The polarization curves for the biofuel cell was obtained from the use of a series of external loads ( $1 \mathrm{M} \Omega$ to $1 \mathrm{k} \Omega$ ). The bioanode and biocathode were constructed using $\mathrm{Pd}$ nanowires and positioned $20 \mathrm{~mm}$ apart in the single compartment cell. The glucose oxidase selectively catalyzes glucose oxidation in the presence of oxygen and laccase catalyzes oxygen reduction reaction at the cathode, thereby enabling the use of a single compartment design for testing. All current densities were calculated using geometrical area of the bioelectrodes. 


\subsection{Morphological characterizations}

The morphology and structural characteristics of the AAO template and electrodeposited Pd nanowires were characterized by atomic force microscopy (AFM) using an Agilent 5500 Scanning Probe Microscope (Agilent Technologies, USA) and scanning electron microscopy (SEM) using Hitachi SU70, respectively.

\section{Results and discussion}

\subsection{Characterization of bioelectrodes}

An AFM top-view micrograph of the AAO template is provided in Scheme 1 with throughout pores in highly ordered hexagonally arrangement. The pore diameters range from 62 to $70 \mathrm{~nm}$. The depth of the AAO pore is about $98 \mu \mathrm{m}$, which is also equal to the thickness of the freestanding porous AAO film. It can be seen that the pores are surrounded by six oxides pillars, which are interconnected to form a hexagonal closed pack network. In addition, these fabricated AAO templates are inherently ordered in nature and the highly self-arranged hexagonal array that permit them to be used as a template for the electrodeposition of metal species, such as Pd [23]. The current transient for deposition of Pd into the pores is shown in Scheme 1B. From the current transient plot, we observed the charging of the double layer by the hydrogen-bonded hydronium ions $\left(\mathrm{H}_{3} \mathrm{O}^{+}\right)$followed by $\left[\mathrm{PdCl}_{4}\right]^{2-}$ ions on the negatively charged Au electrode at the bottom of the AAO template. This initial Pd-Au interaction results in the initial steep drop in the current density. This observation is collaborated with double-layer charging observed during electrodeposition of other metals [24-25]. Upon charging of the double layer, the current density begins to increases nonlinearly with time as $\left[\mathrm{PdCl}_{4}\right]^{2-}$ ions are reduced by accepting electrons from the $\mathrm{Au}$ substrate through hydrogen-bonded $\mathrm{H}_{3} \mathrm{O}^{+}$ions. Thus, it can be observed that the deposition of $\mathrm{Pd}$ nanowires is not a steady state process. The discharging of Pd atoms forms the nuclei on the Au substrate, which results in the diffusion controlled deposition of Pd atoms on the Au electrode [22].

Scheme 1C shows the SEM micrograph of free standing vertically aligned metal Pd nanowire arrays in relatively large area obtained upon completely etching away the AAO template. The electrodeposited Pd nanowire array synthesized in the AAO template resulted in the negative replication of the honeycomb structure of the AAO template (Scheme 1D). The diameter of Pd nanowires is expected to be equal to that of the pores in which the Pd nanowires were produced. An average diameter of $64 \mathrm{~nm}$ with a symmetric distribution and an average length of $5.6 \mu \mathrm{m}$. The electrodeposition process resulted in unequal lengths of Pd nanowires because the length obtained is highly influenced by

deposition time, diffusion and inhibition by the products formed. The Pd nanowire density is $2 \times 10^{9} \mathrm{~cm}^{-2}$, which is an important factor for the performance of the bioanode since it provides a larger electroactive surface area, thus resulting in higher catalytic capability of the enzymes.

The bioanode and biocathode surfaces were prepared by incubating $1 \mathrm{mg} / \mathrm{ml}$ glucose oxidase and $0.5 \mathrm{mg} / \mathrm{ml}$ catalase and $1 \mathrm{mg} / \mathrm{ml}$ laccase in PBS, respectively. Catalase was also immobilized at the bioanode to remove the excess of hydrogen peroxide produce as a byproduct of the oxidation of glucose fuel. The enzyme layer was prepared directly on the $\gamma$-APS-aldehyde functionalized Pd nanowires via EDC/ PEG-NHS coupling. The resulting immobilized enzyme bioelectrodes were encapsulated with a hydrogel composite membrane. The hydrogel composite membrane was effectively integrated with the $\gamma$-APS-aldehyde functionalized Pd nanowire array bioelectrode surfaces through surface functionalization and crosslinking. The underlying Pd nanowire array bioelectrode maintains high surface area after coating with hydrogel composite membrane.

\subsection{Nonenzymatic and enzymatic bioanodes}

The enzymatic bioanode exhibit higher current density than the nonenzymatic bioanode at $600 \mathrm{mV}$ vs. Ag/AgCl. The lower anodic current generated by the nonenzymatic bioanode may be attributed to the formation of metal oxide of the 
surface of the bare Pd bioanode. This further suggests that the electron transfer process requires an application of a larger potential due to the resistive nature of the metal oxide to passage of currents. This large overpotential limited the amount of power generated as well as resulted in large biofuel cell voltage drop, thereby limiting the nonenzymatic bioanode application in glucose/ $\mathrm{O}_{2}$ fuel cells. Glucose oxidase and catalase were co-immobilized on the Pd nanowires in order to address this limitation of the nonenzymatic Pd bioanode. The current density at $600 \mathrm{mV}$ was double than that of the nonenzymatic bioanode.

Cyclic voltammetry measurements were performed in $5 \mathrm{mM}$ glucose to compare and evaluate the electrocatalytic activity of the nonenzymatic and enzymatic bioanodes in a classical three electrode arrangement containing the reference electrode $\mathrm{Ag} / \mathrm{AgCl}\left(\mathrm{KCl}_{\text {sat }}\right)$ and a counter Pt electrode. In principle, the combination of glucose oxidase and Pd nanowire arrays leads to the development of a glucose oxidase bioanode that can oxidize glucose, enhance the bioanode conductivity and facilitate the electron transfer of the biocatalyst without the use of a mediator [26]. Figure 1 represents the cyclic voltammograms (CVs) of the GOx-Pd and bare Pd bioanodes measured in air-saturated 0.1 M PBS and air-saturated glucose $5 \mathrm{mM}$ with a scan rate of $20 \mathrm{mV} / \mathrm{s}$. The $\mathrm{CV}$ profile in phosphate buffer saline for both bioanodes were nearly featureless. In the presence of $5 \mathrm{mM}$ glucose, an increase in the electrocatalytic current for the bare Pd nanowires was observed in the potential range of 0.3 to $0.8 \mathrm{~V}$, which suggest the oxidation of glucose and the cathodic peak at $-0.14 \mathrm{~V}$ is attributed to the reduction of the palladium oxide formed at higher potential during the forward scan [20]. Surface confined redox processes associated with the presence of glucose oxidase were apparent in the CV of the GOx-Pd nanowires in the presence of $5 \mathrm{mM}$ glucose. The anodic current increased, suggesting catalytic activity towards glucose.

Additional CVs were performed with the enzymatic bioanode in different glucose concentration to evaluate the electrocatalytic activity of the GOx-Pd bioanode. Figure 2 represents the CVs of the GOx-Pd bioanode measured in airsaturated $0.1 \mathrm{M}$ PBS and glucose: $1 \mathrm{mM}, 5 \mathrm{mM}$ and $10 \mathrm{mM}$. In the presence of increasing glucose concentration the shape of the $\mathrm{CVs}$ changes considerably. In the presence of glucose, an onset potential was observed at ca. $-0.3 \mathrm{~V} \mathrm{vs}$. $\mathrm{Ag} / \mathrm{AgCl}$ for glucose oxidation. Thereby suggesting that this redox system exhibits an increase in the electrocatalytic current as a function of glucose concentration, and thus corresponds to glucose oxidation. The electrocatalytic current generated in the presence of $5 \mathrm{mM}$ glucose in air-saturated PBS, oxygen-purged PBS and nitrogen-purged PBS under physiologic conditions ( $\mathrm{pH} 7$ and $37^{\circ} \mathrm{C}$ ) is shown in Figure 3. A large anodic and cathodic currents were observed in the presence of oxygen because oxygen accepts electrons from glucose oxidase, while such large current was not observed in nitrogenpurged PBS containing $5 \mathrm{mM}$ glucose and $5 \mathrm{mM}$ glucose in air-saturated PBS. These results reveal that GOx-Pd nanowires exhibit electron transfer activity without the use of mediators. Thus, the GOx-Pd nanowire bioanode is well suited for use in a single compartment enzymatic glucose biofuel cells.

\subsection{GOx-Pd based glucose/ $\mathrm{O}_{2}$ biofuel cell}

As demonstrated above, the higher current density generated by the GOx-Pd bioanode makes it promising as a bioanode in glucose/ $\mathrm{O}_{2}$ biofuel cells. The GOx-catalase-Pd bioanode and the laccase-Pd biocathode were assembled into a single compartment biofuel cell using glucose prepared in PBS as the electrolyte (Figure 4A). The open circuit voltage $\left(\mathrm{V}_{\text {oc }}\right)$ of the biofuel cell constructed using bare Pd nanowires was $13.4 \mathrm{mV}$, this makes the bare Pd nanowires impractical for improving $\mathrm{V}_{\mathrm{oc}}$ of the biofuel cell and maximizing the power generated. Here, we developed a glucose/ $\mathrm{O}_{2}$ biofuel cell using the GOx-Pd bioanode which exhibits a more favorable improvement of $\mathrm{V}_{\mathrm{oc}}$ of the biofuel cell. Figure $4 \mathrm{~B}$ shows the $I-V$ and power characteristics of the glucose biofuel cell at different external loads $(1 \mathrm{k} \Omega$ to $1 \mathrm{M} \Omega)$ in $1 \mathrm{mM}, 5 \mathrm{mM}$ and $10 \mathrm{mM}$ glucose solution saturated with air. The open circuit voltage of the fuel cell was 322,389 and $506 \mathrm{mV}$ for $1 \mathrm{mM}, 5 \mathrm{mM}$ and $10 \mathrm{mM}$ glucose, respectively. The power of the cell at different loads obtained with various glucose concentrations is shown in the Figure 4B. The maximum power densities were $10.5 \mu \mathrm{W} / \mathrm{cm}^{2}$ at $0.20 \mathrm{~V}(1 \mathrm{mM}$ glucose $), 18.8 \mu \mathrm{W} / \mathrm{cm}^{2}$ at $0.17 \mathrm{~V}\left(5 \mathrm{mM}\right.$ glucose), and $72.2 \mu \mathrm{W} / \mathrm{cm}^{2}$ at $0.25 \mathrm{~V}(10 \mathrm{mM}$ glucose). The results observed here follows the trends of the bioanode for the oxidation of glucose when tested separately in a three-electrode cell setup for CV characterization (Figure 2). The short circuit current densities were $136 \mu \mathrm{A} / \mathrm{cm}^{2}, 233 \mu \mathrm{A} / \mathrm{cm}^{2}$, and $411 \mu \mathrm{A} / \mathrm{cm}^{2}$, for $1 \mathrm{mM}, 5 \mathrm{mM}$ and $10 \mathrm{mM}$ glucose, respectively. These values compare well with those recently reported for other glucose biofuel cells based on immobilized enzymes [27-29]. The cell performance operating in $5 \mathrm{mM}$ glucose under $\mathrm{O}_{2}$-saturated condition exhibited an 
overall stable current density profile, wherein the current density dropped by $21 \%$ over a period of five weeks in $5 \mathrm{mM}$ glucose. This stability could be attributed to the large electroactive surface area afforded by the Pd nanowire array electrodes and the fast electron transfer between the enzymes and electrodes. There is clearly an enhanced cell performance as the concentration of the glucose fuel increases.

\section{Conclusion}

In this study, highly ordered Pd nanowire bioelectrodes were synthesized by electrochemical deposition of Pd in order to develop a single compartment glucose biofuel cell. The AFM and SEM characterizations indicate that the Pd nanowires were uniformly assembled into the hexagonally arranged nanopores of the AAO. The biofuel cell was based on glucose oxidase and catalase bioanode and a laccase biocathode using Pd nanowire array bioelectrodes. This GOx-Pd nanowire glucose biofuel cell provided an efficient electron transfer bioelectrocatalytic system and can serve as an alternative to using CNTs (buckypaper) which are fragile [30-31]. The two-dimensional array of Pd nanowires exhibit large surface area that can improve enzyme loading. The maximum power density obtained was $72.2 \mu \mathrm{W} / \mathrm{cm}^{2}$ at $0.25 \mathrm{~V}$ was obtained in air-saturated solution with $10 \mathrm{mM}$ glucose. At physiologic glucose concentration $(5 \mathrm{mM})$, an open-circuit potential of $389 \mathrm{mV}$ and a maximum power density of $18.8 \mu \mathrm{W} / \mathrm{cm}^{2}$ at $0.17 \mathrm{~V}$ was obtained. These results lead to the conclusion that GOx-Pd nanowire bioelectrode is a very attractive platform for biofuel cells because no mediators are used. Other biocatalyst that are insensitive to oxygen, such as glucose dehydrogenase may be investigated in order to optimize the power density achieved with the Pd nanowire bioelectrode in the biofuel cell system.

\section{Acknowledgment}

This work was supported by National Science Foundation (Award ECCS-\# \#1349603).

\section{References}

1. Slaughter, G., Sunday, J., 2014. Sensors Journal, IEEE., 14, 1573-1576.

2. Brahim, S., Slaughter, G., Guiseppi-Elie, A., 2003. Proc. SPIE Int. Soc. Opt. Eng. 5053, 1-12.

3. Guiseppi-Elie, A., Brahim, S., Slaughter, G., Ward, K., 2005. Sensors Journal, IEEE., 5, 345-355.

4. Slaughter, G., Amoah, K., 2012. J Biosens Bioelectron, 3, 124.

5. Yang, M., Qu, F., Lu, Y., He, Y., Shen, G., Yu, R., 2006. 27, 5944-5950.

6. Kobayashi, Y., Hoshi, T., Anzai, 2001. 49, 755-757.

7. Rahman, M.M., Shiddiky, M., Rahman, A., Shim, Y., 2009. Analytical Biochemistry, 384, 159-165.

8. Li, C., Dong, H., Cao, X., Luong, J., Zhang, X., 2007. Curr Med Chem, 14, 937-951.

9. Yan, Y., Zhen, W., Su, L., Mao, L., 2006. Adv Mater., 18, 2639-2643.

10. Ivnitski, D., Branch, B., Atanassov, P., Apblett, C., 2006. Electrochemistry Communications, 8, 1204-1210.

11. Davis, F., Higson, S.P.J., 2005. Biosens. Bioelec., 21, 1-20.

12. Katz, E., Willner, I., Kotlyar, A.B., 1999. J. Electroanal. Chem., 479, 64-68.

13. Tsujimura, S., Kano, K., Ikeda, T., 2002. Electrochemistry, 70, 940-942.

14. Kim, H.H., Mano, N., Zhang, Y., Heller, A., 2003. J. Electrochem. Soc. 150, A209-A213.

15. Mano, N., Mao, F., Heller, A., 2003. J. Am. Chem. Soc., 125, 6588-6594.

16. Heller, A., 2004. Phys Chem Chem Phys, 6, 209-216.

17. Kim, J., Jia, H., Wang, P., 2006. Biotechnol Adv, 24, 296-308.

18. Katz, E., Willner, I., 2003. Biofuel cells based on monolayer-functionalized biocatalytic electrodes. In: Geckeler, K.E., editor. Advanced macromolecular and supramolecular materials and processes. New York: Kluwer Academic/Plenum Publishers; 175-196.

19. Cai, Z-X.,, Lui, C-c., Wu, G-c., Chen, X-m., Chen, X., 2013, Electrochimica Acta. 112, 756-762.

20. Chen, X-m,., Cai, Z-c, Huang, Z-y, Oyama, M., Jiang, Y-q, Chen, X., 2013, Electrochimica Acta, 398-403.

21. Sun, Z., Cheng, F., Dai, X., 2009. J Autom Methods Manag Chem. 49, 62-81.

22. Tasaltın, N., Ozturk, S., Kilinc, N., Yuzer, H., Ozturk, Z., 2010. Nanoscale Research Letters. 5, 1137-1143. 
23. Rabin, O., Herz, P., Lin, Y., Akinwande., A., Cronin, S., Dresselhaus, M., 2003. Adv. Funct. Mater. 13, 631-638.

24. Zoval, J., Stiger, R., Biernacki, P., Penner, R., 1996. J Phys. Chem. 100, 837-844.

25. Bera, D., Kuiry, S., Seal, C., 2004. J Phys. Chem. B 108, 556-562.

26. Barton, S., Gallaway, J., Atanassov, P., 2004. Chem Rev. 104, 4867-4886.

27. Yehezkeli, O., Tel-Vered, R., Raichlin, S., Willner, I., 2011. ACS Nano. 5, 2385-2991.

28. Li, L., Liang, B., Li, F., Shi, J., Mascini, M., Lang, Q., Liu, A., 2013. Biosens Bioelectron, 42, 156-162.

29. Lang, Q., Yin, L., Shi, J., Li, L., Xia, L., Liu, A., 2014. Biosens Bioelectronics, 51, 158-163.

30. Bunte, C., Rühe, J., 2009. Macromol. Rapid Commun., 30 (21) 1817-1822.

31. Hussein, L., Urban, G., Kruger, M., 2011. Phys. Chem. Chem. Phys. 13, 5831-5839.

\section{Figure legends}




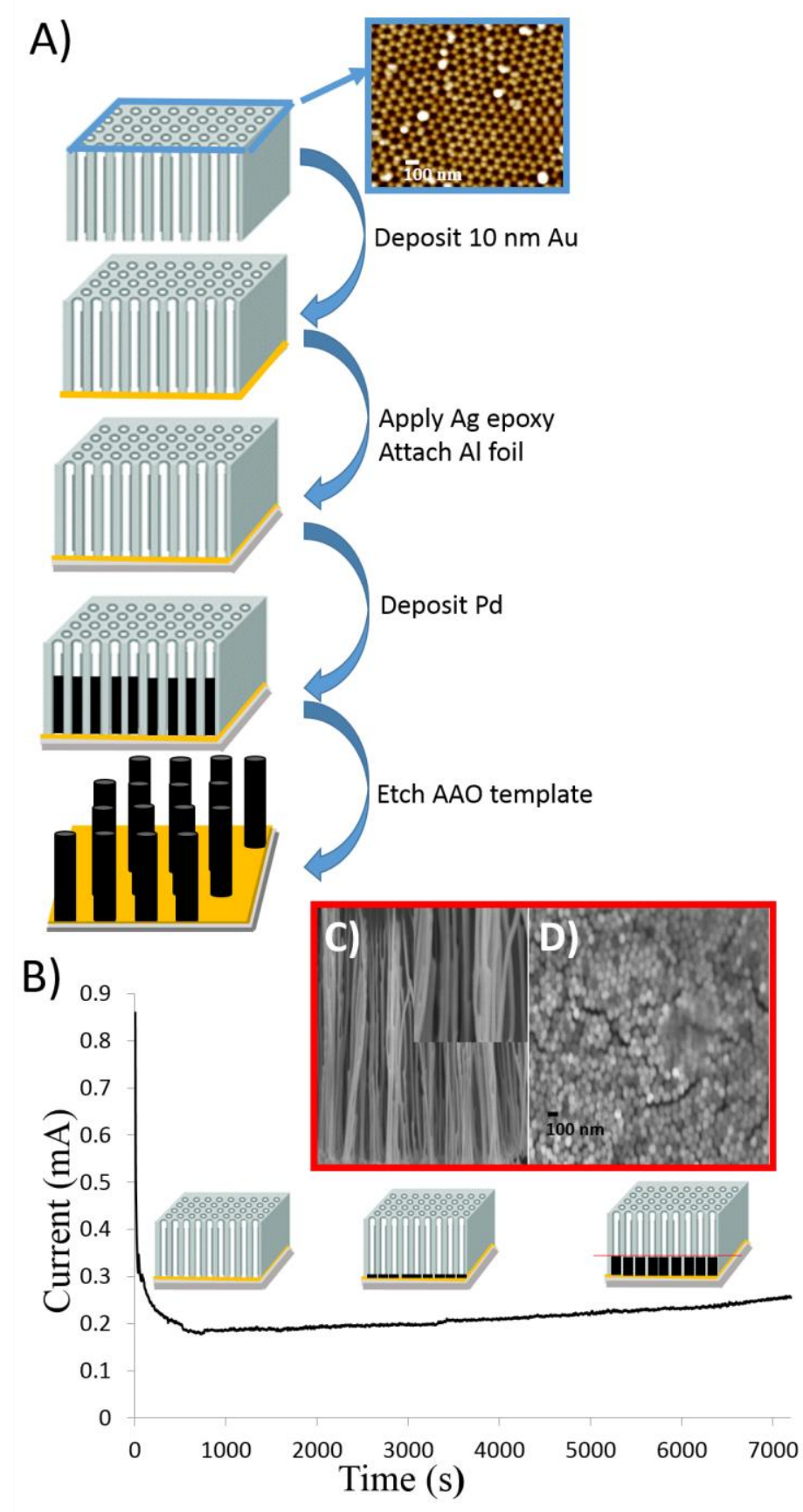

Scheme 1. A) Schematic representation of the electrodeposition of Pd nanowire using AAO template. Top right: AFM top-view micrograph of the AAO template with pore diameter ranging from $62-70 \mathrm{~nm}$. B) Current transient curve for the electrochemical deposition of the Pd into the AAO template. C) SEM cross-sectional view and (D) Top-view micrographs of free standing Pd nanowires after etching away the AAO template in $2 \mathrm{mM} \mathrm{NaOH}$. 


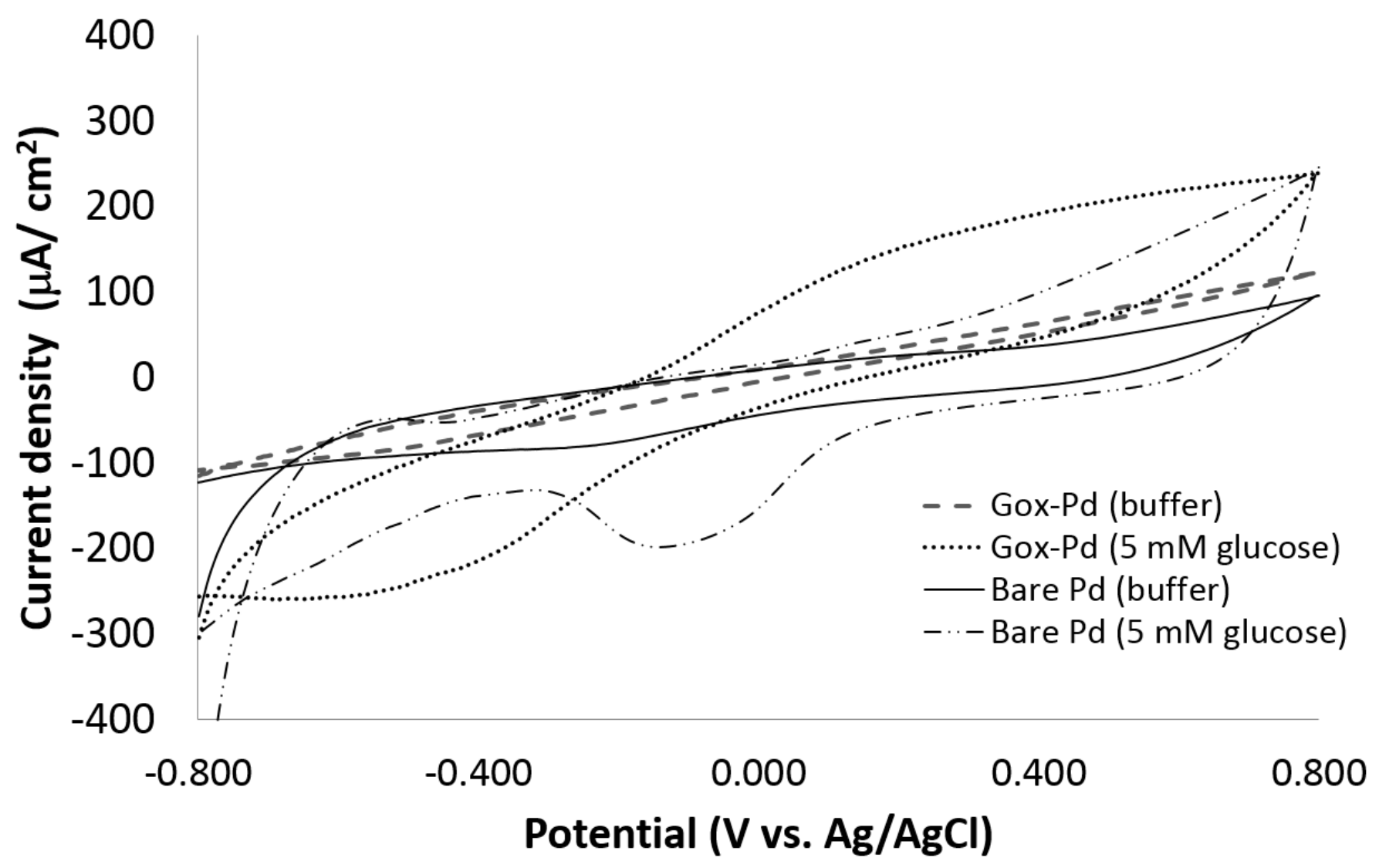

Figure 1. Cyclic voltammograms of the bare Pd and GOx-Pd bioanodes measured in air-saturated $0.1 \mathrm{M}$ PBS and airsaturated $5 \mathrm{mM}$ glucose under physiologic conditions ( $\mathrm{pH} 7$ and $37^{\circ} \mathrm{C}$ ). Scan rate: $20 \mathrm{mV} \mathrm{s}{ }^{-1}$. 


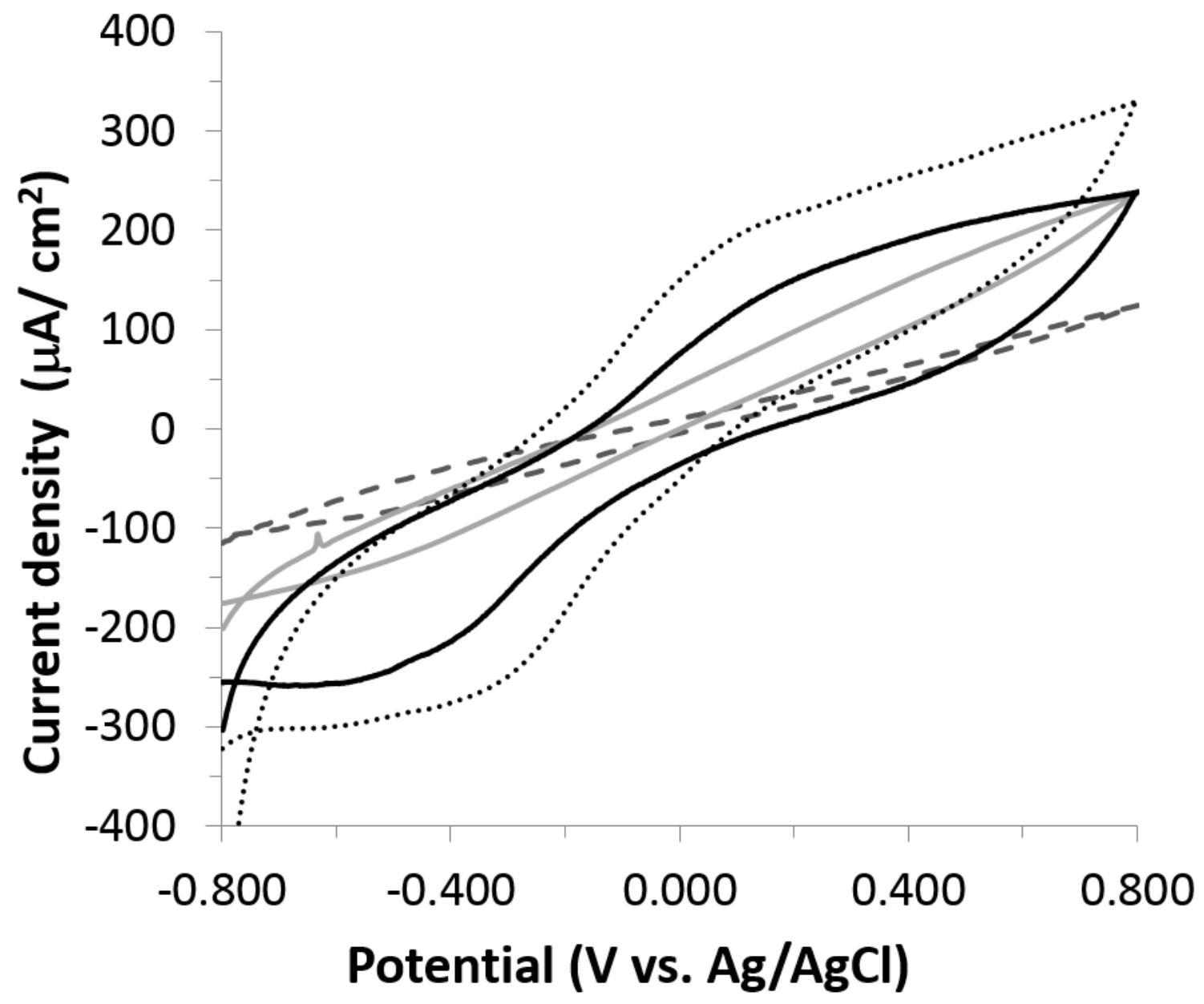

Figure 2. Cyclic voltammograms of the GOx-Pd bioanode measured in air-saturated 0.1 M PBS (dashed line) and airsaturated glucose: $1 \mathrm{mM}$ (gray line), $5 \mathrm{mM}$ (black line) and $20 \mathrm{mM}$ (dotted line) under physiologic conditions (pH 7 and $\left.37^{\circ} \mathrm{C}\right)$. Scan rate: $20 \mathrm{mV} \mathrm{s}^{-1}$. 


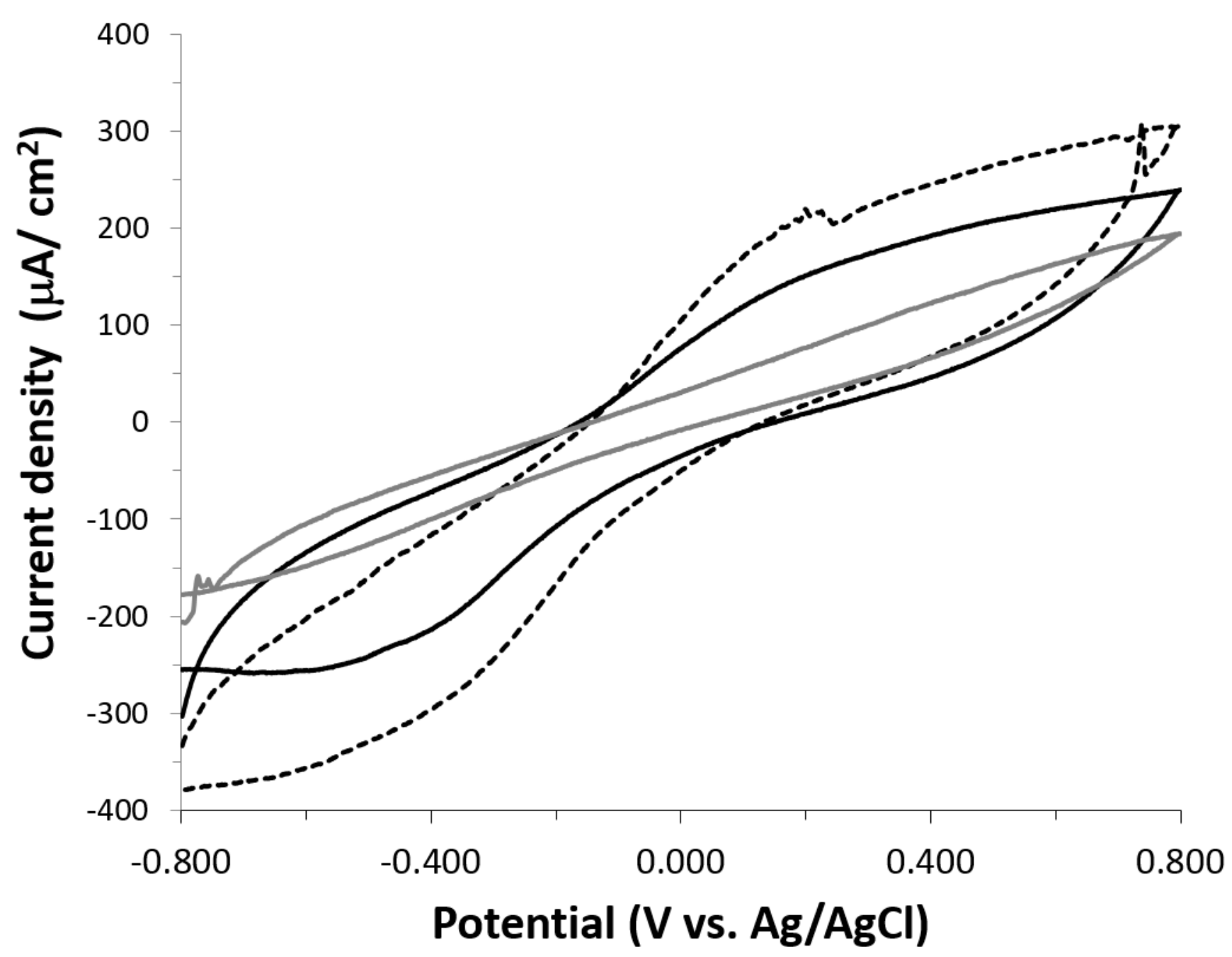

Figure 3. Cyclic voltammograms of the GOx-Pd bioanode measured in the presence of $5 \mathrm{mM}$ glucose in air-saturated PBS (black line), oxygen-purged PBS (dash line) and nitrogen-purged PBS (gray line) under physiologic conditions ( $\mathrm{pH}$ 7 and $\left.37^{\circ} \mathrm{C}\right)$. Scan rate: $20 \mathrm{mV} \mathrm{s}^{-1}$. 

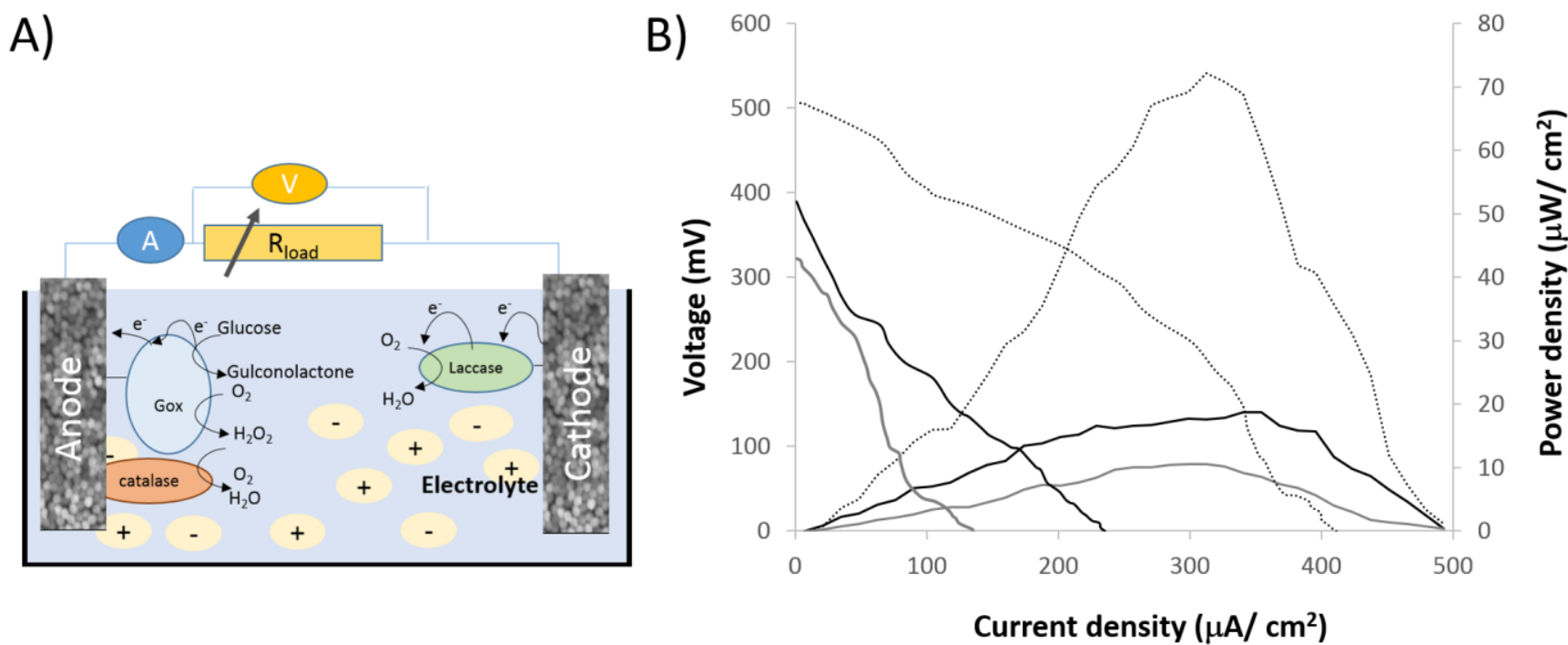

Figure 4. A) Schematic representation of the glucose biofuel cell structure. B) IV and power density curves of the glucose biofuel cell at different external loads in $1 \mathrm{mM}$ (gray line), $5 \mathrm{mM}$ (black line) and $10 \mathrm{mM}$ (dotted line) glucose in PBS $\left(\mathrm{pH} 7\right.$ and $37^{\circ} \mathrm{C}$ ) saturated with air. 


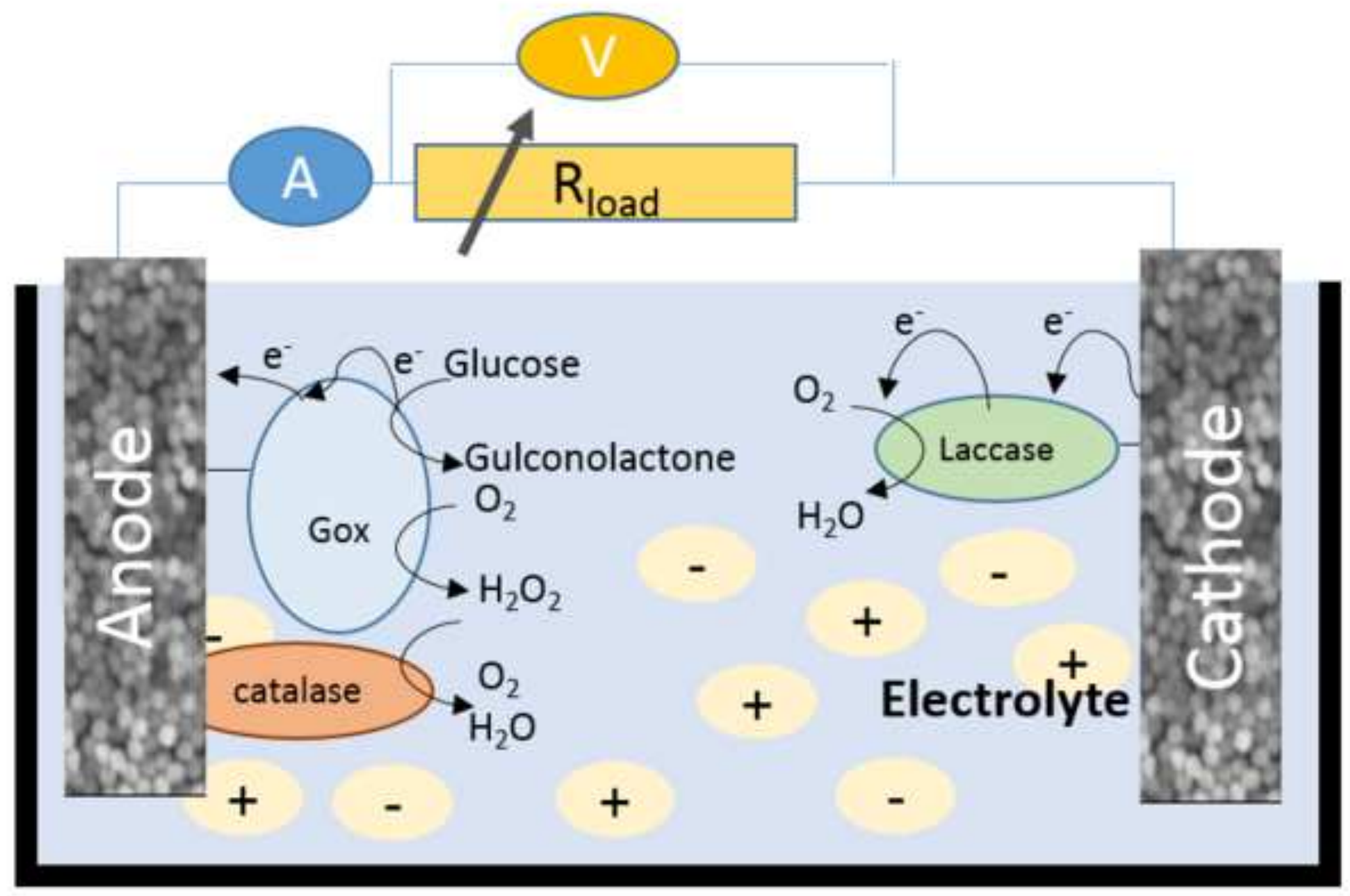

